congenital defects, both in the patches of medullated nerve fibres and in the increase of connective tissue around both discs. There is also the fact that the eyes have normal vision, and manifest no pathological change in any other part of the fundi. Again, there are no signs of recent changes along the vessels or in the neighbourhood of the aneurisms, such as one would expect to find had the disease been progressive, and although the period during which I had the patient under observation (three weeks in all) was too short to be of any help in deciding this point, the condition certainly did not alter, as far as I could judge.

The possibility of this being an early stage in the condition known as arterio-venous aneurism (18 cases of which have been collected and discussed by Coats in his paper in the Royal London Ophthalmic Hospital Reports, Vol. XVIII, on massive exudative retinitis), should, I think, be mentioned, although beyond the fact that this disease mostly attacks healthy males of from 22 to 23 years of age, and that it is generally bilateral, there is no similarity either in the history or in the ophthalmoscopic appearances to the case under discussion. The veins in this case have no connection whatever with any of the aneurisms. A case showing venous communication, together with a patch of medullated nerve fibres was, I believe, reported in one of the ophthalmic journals some years ago.

Referring for a moment to the symptoms complained of by the patient, I do not think these had any connection with the changes found in both fundi, but are more probably attributable to the remaining traces of his nystagmus.

In conclusion, I should like to express my thanks to Col. W. T. Lister, C.M.G., consulting ophthalmic surgeon to the British Expeditionary Force, for his interest in the case, and for his confirmation of the ophthalmoscopic appearances.

\title{
BILATERAL GLIOMA OF THE RETINA WITH MULTIPLE METASTASES.*
}

BY
Frank E. Taylor, M.D., and Norman B. B. Fleming, F.R.C.S.,
PATHOLOGIST AND CURATOR TO THE ROYAL WESTMINSTER OPHTHALMIC HOSPITAL.
M.B., Ch.B.,
LIEUT., R.A.M.C.; CLINICAL ASSISTANT TO THE ROYAL WESTMINSTER OPH- THALMIC HOSPITAL.

A CRITICAL examination of the collected statistics of Wintersteiner ${ }^{1}$ on glioma of the retina reveals the fact that when malignant characters are borne by this neoplasm they are shown by the extension and spread of the new growth in two ways, namely:-

\footnotetext{
*A paper read before the Royal Society of Medicine (Section of Ophthalmology) on
} Nov. 1st, 1916. 
(1) By involvement of the extra-orbital structures of the face and head, either by $(a)$ direct continuity of growth into the bones and other structures adjacent to the orbital cavity; or $(b)$ direct extension of the growth backward into and along the optic nerve to the meninges and the brain; or (c) the occurrence of growths in the lymphatic glands in the neighbourhood of the parotid gland, and also occasionally the involvement of that organ.

(2) By the formation of metastatic growths in various organs in distant parts of the body.

That the former condition (1) is much more frequently observed than the latter is also shown by Wintersteiner's figures. Out of a total of 497 cases of glioma of the retina, regional invasion occurred :-

In the bones of the cranium and face in 40 cases.

In the brain and meninges in 43 cases.

In the adjacent lymph glands in 46 cases.

In the parotid gland in 9 cases.

In the spinal cord and membranes in 3 cases.

Whereas metastases (2) in distant organs were found :-

In the skeletal bones in 9 cases.

In the liver

in 7 ,

In the ovary

In the kidney

In the lungs

In the spleen

in $2 "$,
in $2 "$
in $1 "$
in 1 ",

Further, in addition to our own case here recorded, in which metastases occurred in the brain and meninges, in the vertebræ, in the mesenteric glands, and in the ovary, we are able to find only five cases recorded since those collected by Wintersteiner, in which metastases in distant organs were found.

In Fehr's ${ }^{2}$ case the metastatic growths occurred in the ribs, sternum, and pleura, in the inguinal and mediastinal lymph glands, and nodules were also found between the left lung and pericardium, and adherent in the anterior mediastinum.

In Radcliffe and Goldberg's ${ }^{3}$ case metastases were found in the liver, and in Lieber's $\mathrm{s}^{4}$ case in the lungs.

Dabs's ${ }^{5}$ case is buried in the obscurity of a Greifswald thesis to which we are unable to gain access; we are therefore unable to state the distribution of the metastatic growths.

In Gardner's ${ }^{6}$ case the organs affected were the sternum, ribs, costo-chondral cartilages, vertebræ, pelvic bones, both femora, and both testicles.

With regard to the frequency of bilateral growths, the collected statistics of Owen ${ }^{7}$ show the condition to be bilateral in rather less than 25 per cent. of the cases, for out of a total of 552 cases, 417 were unilateral, and 135 were bilateral. 
Four facts connected with the following case are of sufficient interest to make it worthy of being placed on record, namely :-

(1) The presence of advanced growths in both eyes at the same time.

(2) The very advanced condition of the growths when the patient was first brought up for treatment.

(3) The presence of metastatic growths, both by direct extension into the brain and meninges and by metastases in the vertebræ, mesenteric glands, and ovary.

(4) The relatively small amount of shock and other disturbance which followed so severe an operation as complete evacuation of both orbits in so young a patient.

The history of our case is as follows :-

Lilian D., aged 3 years, was sent to the Royal Westminster Hospital on the 14th February, 1916, and was seen by Mr. Elmore W. Brewerton, who ordered her immediate admission into Hospital.

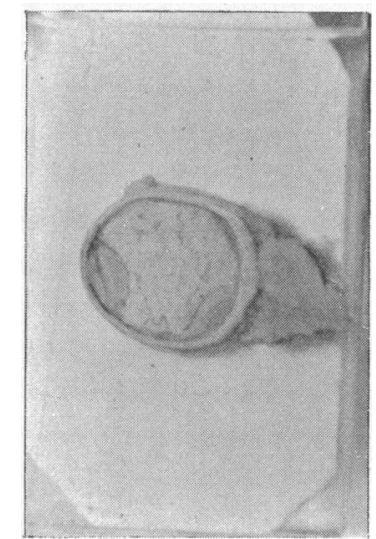

FIG. 1.

Section of Right Eye.

Something abnormal in the left eye was first noticed eighteen months previously, probably in September, 1914. No advice was sought till September, 1915, when she was taken to the Royal Surrey County Hospital at Guildford. The mother states that she was then refused treatment, on the ground that it was useless. The child had not been fretful, was fairly well nourished, and ate and slept well.

On admission, a fungating growth protruded between the lids of the left eye, keeping them separate; it had been fungating for three months. The mass was moist with a thin, semi-purulent discharge.

The right eye was much enlarged and apparently proptosed. The iris was fully dilated and stretched into a thin band at the limbus. The lens was in contact with the posterior aspect of the cornea, being pushed forward by a growth behind. The latter was of a 
lemon-yellow colour, as seen by ordinary daylight, and also by oblique focal illumination. On ophthalmoscopic examination, no reflex was obtained.

As regards treatment, an operation was performed within an hour

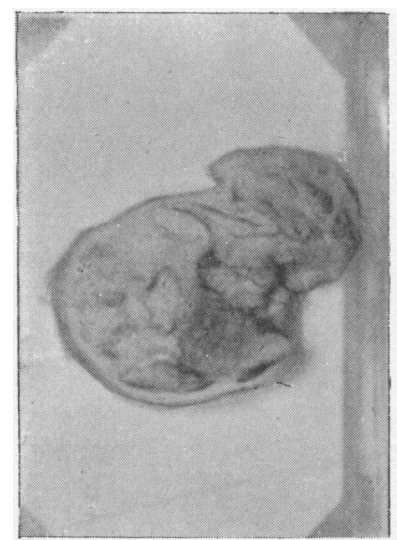

FIG. 2 .

Section of Left Eye.

of admission. The left orbit was exenterated. The lids were partly removed, and the wound stitched up, an aperture being left for packing.

The right eye was very freely excised. The conjunctiva was removed and the optic nerve was divided three-quarters of an

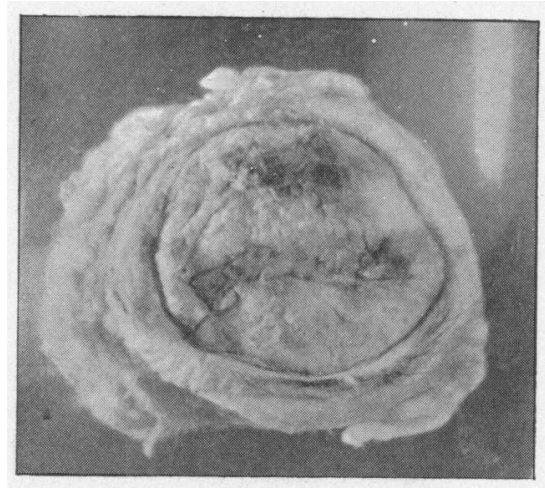

Fig. 3.

Recurrence from Right Socket.

inch behind the globe. The nerve was found to be involved, being surrounded by growth for half an inch behind the eye.

The right socket healed readily. The left socket became septic, 
and the discharge had an unpleasant odour, but rapidly improved under irrigation with hydrogen peroxide and dressing with iodoform.

On the 11th March the child was discharged, there being as yet no sign of recurrence in either socket. While in Hospital, there was some bronchitis, which was recovered from, and at all times food was taken with avidity. The patient was re-admitted on the 30th March with a large recurrence, equal in size to half a tennis ball, protruding from the right orbit. The left orbit was completely covered with skin, but, with a little pressure, a solid mass could be felt in the socket. The same day the right orbit was thoroughly cleared out, the greater part of the lids being removed at the same time. By this time the child was thinner, and tended to be fretful. She took the anæsthetic very badly and stopped breathing, but artificial respiration was successfully carried out. A general anæs: thetic was required subsequently for the first two dressings, and the same difficulty with respiration was experienced. After this, the child's condition improved, but a muco-purulent nasal catarrh developed, which persisted until death supervened about eight weeks later. The discharge was incessant, and before the end, caused much excoriation of the face. The head was noticed to be disproportionately large, and emaciation was very marked.

The right socket quickly filled up again and the growth in the left one infiltrated the skin and became fungating, and both orbits were again cleared out on May 1st. The greater part of the growths was found to consist of a material which had undergone pseudomyxomatous degeneration.

After the final operation, the child quickly went downhill. She became quite apathetic, and neither ate nor slept. On the 3rd May she was found to have pneumonia of the left lung, but there were no rigors and no rise in temperature or in pulse. She cried a good deal, and her breathing was short and jerky, but there was little to indicate that she was suffering much pain. On the 6th of May the right lung showed signs of consolidation at the base, and death occurred on the evening of the 7th of May.

\section{Pathological Report.}

The tissues removed from the orbits presented the following characters :

Externally the right eye appeared normal except for a mass of new growth on the posterior aspect of the globe, embedded in which was the excised portion of the optic nerve. This mass was triangular in shape, being half an inch wide and half an inch from before backwards. On section, the coats of the eye appeared normal, but the anterior chamber was very shallow, the lens being pushed forward by a greyish-white growth which completely filled the vitreous chamber (Fig. 1). 
The left eye was enlarged and filled by a soft mass of new growth, which was everywhere confined within the coats of the eye, except in front where the lens and structures in front of it were missing, and the growth projected forwards between the lids, the surface being ulcerated and excavated (Fig. 2). The posterior half of the neoplasm was of greyish-white colour, whilst the anterior half was of a dark brownish-red colour, as if infiltrated with blood. The structures of the eye, except the sclera, were entirely unrecognisable.

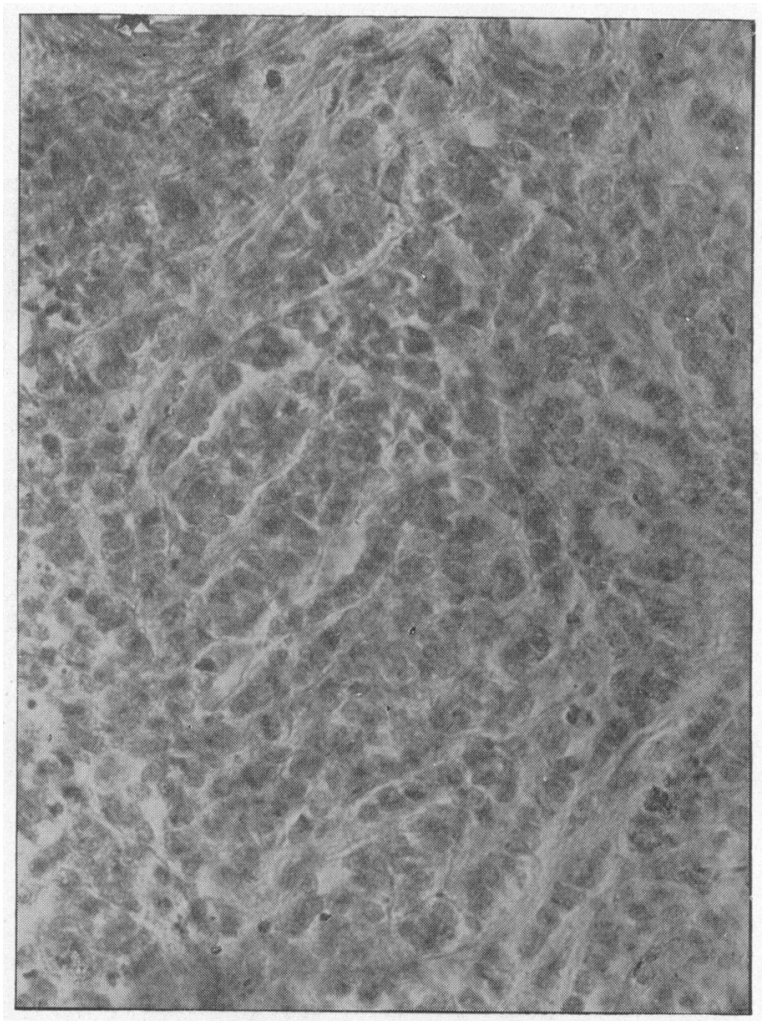

FIG. 4.

Section of Glioma of Eye, showing masses of more or less deg enerated round cells (feebly staining). $\times 320$.

Microscopically, the growths were composed of closely packed small round cells, with large deeply-staining nuclei, and extremely little surrounding cytoplasm. A few spindle cells were also present. Small syncytial masses, with multiple nuclei, forming the so-called giant-cells, were scattered irregularly through the mass in scanty numbers. The intercellular stroma was extremely small in amount, being almost unrecognisable. There was much hæmorrhagic 
extravasation into the growth, although blood-vessels were few in number. Neuro-epithelial rosettes were not found in the sections.

The choroid and optic nerve in both eyes were infiltrated with growth, as was the left upper eyelid.

In the right eye the structures anterior to the posterior capsule of the lens were quite free from growth.

\section{Post-Mortem Examination.}

The body was that of an exceedingly emaciated female child, showing an extensive impetiginous rash on the face; both orbits, having been recently exenterated, showed gaping hollows, revealing the base of the sphenoid.

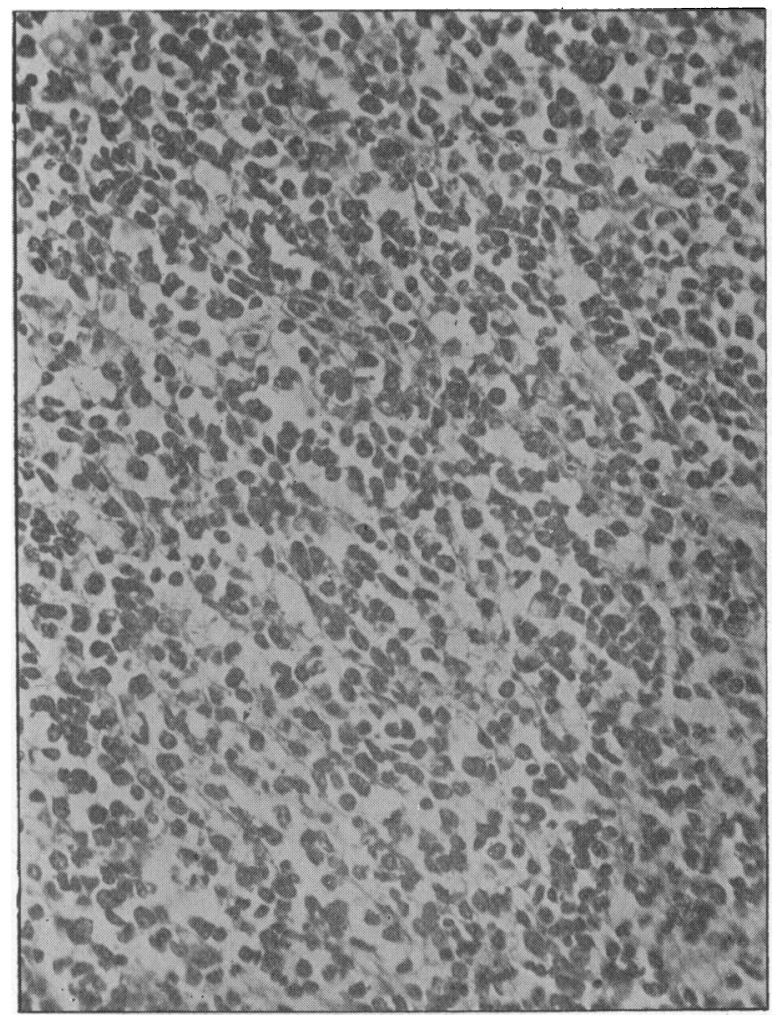

FIG. 5.

Section of secondary Tumour of Ovary, showing structure of round-celled Sarcoma. $\times 320$

Removal of the calvarium was difficult, on account of the bone being adherent to the dura mater. This was found to be due to many (about twenty) curious-looking growths, round in outline, some of 
them discrete and some coalescing. They were about $\frac{1}{4}$ of an inch in thickness, bright-red in colour, like healthy granulations, and they varied from $\frac{1}{4}$ of an inch to 2 inches in diameter. The pia mater was hyperæmic in those areas, but apart from this, the convexity showed nothing abnormal. The brain weighed $2 \mathrm{lbs} .8 \mathrm{oz}$. At the base of the brain, in the position of the optic chiasma, and to some extent obscuring or replacing it, was a large mass of growth covered by pia mater.

The lungs both showed a condition of septic pneumonia. The mesenteric glands were enlarged, and the seat of metastases. In the centre of the right ovary there was a blood-clot, measuring five-sixteenths of an inch in diameter. This was surrounded by an area of new tissue forming a zone, three-sixteenths of an inch in thickness. The right Fallopian tube was normal, as were the left ovary and tube, and also the uterus and vagina. Protruding from the anterior aspect of the body of the second lumbar vertebra was an oval mass of growth, $\frac{3}{4}$ inch by $\frac{1}{2}$ inch, and projecting about $\frac{3}{8}$ inch above the surface of the bone.

The secondary growths in the meninges and in the ovary (Fig. 5) were examined microscopically, and presented the characters of a small round-celled sarcoma, no neuroglial elements being recognisable.

Our thanks are due to Mr. Elmore W. Brewerton for his kind permission to publish this case.

\section{REFERENCES.}

1. Wintersteiner.-." Das Neuro-Epithelioma Retinæ," Leipzig u. Wien, 1897.

2. Fehr.-Centralblatt für prak. Augenheilkunde, 1900, Bd. XXIV, S. 129.

3. Radcliffe and Goldberg.-Archives of Ophthalmology, 1907, Vol. XXXVI, p. 223.

4. Lieber.-Klinische Monatsblätter für Augenheilkunde, 1907, Bd. XIV, S. 270

5. Dabs.-Greifswald Thesis, 1906.

6. Gardner.-A rchives of Ophthalmology, 1908, Vol. XXXVII, p. 657.

7. Owen.-Royal London Ophthalmic Hospital Reports, Vol. XVI.

\section{TRANSLATION.}

\section{Traumatic Rupture of the Ciliary Arteries. (Rupture traumatique} des artères ciliaires.) By MARIE HuguenIn. La Clinique Ophtalmologique, février, 1916, reproduced from Revue Suisse de Médecine (no date given).

The article by Marie Huguenin, of Berne, deals with a subject apparently not well known in this country. On that account it is proposed to make what practically amounts to a translation of parts of the article, in spite of the fact that it is already at second-hand, so to speak.

Siegrist, of Berne, in 1895 gave the first description of traumatic 